DOI: https://doi.org/10.46667/renbio.v13i1.284

\title{
O ensino de nutrição e metabolismo energético a partir de um jogo de tabuleiro denominado Sobrevivência "Versão 1.0"
}

\author{
The teaching of nutrition and energy metabolism from a board game named \\ Survival "Version 1.0" metabolism
}

Thyago Santos de Vasconcelos ${ }^{1}$

Andrea Thompson Da Poian ${ }^{2}$

\begin{abstract}
Resumo
O estudo de nutrição e metabolismo energético no ensino médio depende de uma série de conceitos da química orgânica, que somente será trabalhada no último ano pelo professor de Química. A grande dificuldade dos professores de Biologia é introduzir esses conceitos químicos paralelamente a esse conteúdo. Cremos que apenas as aulas expositivas não sejam suficientes para despertar o interesse dos alunos. Partindo dessa premissa, acreditamos que seja muito relevante o desenvolvimento de novos materiais educacionais com o intuito de melhorar a aprendizagem. "Sobrevivência" é um jogo de tabuleiro de caráter investigativo/cooperativo sobre nutrição e metabolismo energético. Usado como uma estratégia lúdica, ele foi desenvolvido como material pedagógico para auxiliar os professores a revisar conceitos sobre o tema.
\end{abstract}

Palavras-chave: Jogo de tabuleiro. Ensino de Biologia. Nutrição e metabolismo energético.

\begin{abstract}
The study of nutrition and energy metabolism in high school depends on a series of concepts of organic chemistry, which will only be worked on in the last year by the Chemistry professor. The great difficulty for Biology teachers is to introduce these chemical concepts in parallel to this content. We believe that only the lectures are not enough to arouse the interest of students. Based on this premise, we believe that the development of new educational materials is very relevant to improve learning. "Survival" is an investigative / cooperative board game on nutrition and energy metabolism. Used as a playful strategy, it was developed as teaching material to assist teachers in reviewing concepts on the topic.
\end{abstract}

Keywords: Board game. Biology teaching. Nutrition and energy metabolism.

\footnotetext{
${ }^{1}$ Mestrado Profissional em Ensino de Biologia - Rede Nacional PROFBIO. Universidade Federal do Rio de Janeiro (UFRJ) - Rio de Janeiro, RJ - Brasil. Professor da rede municipal de Macaé e da rede estadual Rio de Janeiro, RJ - Brasil. E-mail: thyago99@gmail.com

${ }^{2}$ Doutora em Química Biológica - Universidade Federal do Rio de Janeiro. Universidade Federal do Rio de Janeiro (UFRJ) - Rio de Janeiro, RJ - Brasil. Professora Titular do Instituto de Bioquímica Médica Leopoldo de Meis da Universidade Federal do Rio de Janeiro (UFRJ). Rio de Janeiro, RJ - Brasil. E-mail: dapoian@bioqmed.ufrj.br
}

Submetido em: 04/03/2020 - Aceito em: 15/06/2020

REnBio - Revista de Ensino de Biologia da SBEnBio - ISSN: 1982-1867 - vol. 13, n. 1, p. 42-58, 2020 
DOI: https://doi.org/10.46667/renbio.v13i1.284

\section{Introdução}

O conteúdo de nutrição e bioenergética no ensino médio depende de uma série de conceitos da química orgânica, cujos conteúdos somente serão ministrados, segundo o currículo mínimo de Química do Estado do RJ, na terceira série pelo professor de Química. O grande desafio do professor de Biologia em relação a esse conteúdo é: lidar com a pequena carga horária, seguir o currículo e introduzir alguns conceitos básicos da química orgânica. No currículo mínimo de Biologia do Estado do RJ é sugerido que esse tema seja ministrado no primeiro bimestre da segunda série do ensino médio. Ao lidar com a pequena carga horária e com a necessidade de um conhecimento prévio de química orgânica, o professor tende a resumir alguns conceitos sobre esse conteúdo a partir de equações simplificadas, como a da respiração celular. Essa simplificação pode gerar desinteresse e criar uma aversão à disciplina de Biologia.

Para Krasilchik (2016) "a disciplina biologia pode ser uma das matérias mais relevantes e merecedoras da atenção dos alunos, ou uma das disciplinas mais insignificantes e pouco atraentes, dependendo do que for ensinado e de como isso for feito". Preocupados com essa relação dos alunos com a disciplina de Biologia, pensamos em uma nova estratégia que fosse além da metodologia tradicional. Optamos, então, pela escolha dos jogos didáticos, pois acreditamos que eles facilitam a percepção do conteúdo de uma forma mais estimulante e lúdica.

Assim como Campos et al (2003), consideramos que os jogos didáticos podem ser utilizados para preencher algumas lacunas deixadas pelo processo de transmissão-recepção de conhecimentos que são trabalhados de forma muito rápida em sala de aula. Além disso, os jogos permitem que os discentes reflitam sobre o material didático e sobre o conteúdo, e que estruturem e socializem os seus conhecimentos com os outros. Essas interações possibilitam a formação de conhecimentos novos e mais elaborados. (CAMPOS et al, 2003)

A temática foi escolhida a partir de uma conversa entre os pesquisadores, onde o professor-pesquisador expôs a sua prática diária, através da qual percebia que muitos alunos chegavam ao terceiro ano do ensino médio com a concepção de que a glicose era a única fonte de energia do nosso corpo. Esse equívoco também foi observado por Oliveira (2003) e Luz et al (2008) em suas pesquisas. Essa ideia vai sendo desconstruída ao longo do ano letivo por mim, professor-pesquisador, principalmente quando trabalho temas relacionados à bioenergética, como o funcionamento dos músculos, à qual introduzo outras fontes de energia além dos carboidratos. 
DOI: $\underline{\text { https://doi.org/10.46667/renbio.v13i1.284 }}$

A partir dessa inquietação decidimos pela elaboração e aplicação de um jogo investigativo e cooperativo denominado "Sobrevivência". Ele foi criado a partir de situações cotidianas associadas ao conteúdo de nutrição e metabolismo energético, para que os alunos pudessem ser provocados frente aos desafios reais e, através do trabalho cooperativo pudessem, juntos, vivenciar as experiências importantes para transformar as suas realidades, favorecendo, assim, a construção do conhecimento. Bordenave (2010 p.124) enfatiza que "as atividades são os veículos utilizados pelo professor para criar situações e abordar conteúdos que permitam ao aluno viver as experiências necessárias para a sua própria transformação". Assim sendo, construímos o jogo com essas características, pois consideramos importante que o aluno vivencie e experimente a realidade para que seja possível essa transformação. Uma forma de vivenciar a sua prática diária foi a introdução no jogo de tabelas nutricionais adaptadas, para que o jogador pudesse analisar as informações de alguns alimentos que continham somente proteínas e/ou lipídios e a partir dessas informações eles pudessem concluir que as proteínas e os lipídios fornecem energia, assim como alimentos ricos em carboidratos.

Este jogo didático é recomendado para alunos de ensino médio e deve ser aplicado como forma de revisão, já que ele depende de alguns conhecimentos prévios da temática trabalhada. Seguindo o currículo mínimo do Estado do RJ, esse material didático poderá ser aplicado no fim do primeiro bimestre para alunos do segundo ano do ensino médio, após as aulas sobre as transformações essenciais à vida, onde são trabalhados temas como as formas de obtenção de energia dos seres vivos, como o metabolismo celular energético. A partir do jogo, os discentes aprenderão e/ou revisarão conhecimentos sobre as biomoléculas energéticas (proteínas, carboidratos e lipídios), a função da insulina em nosso corpo, a gliconeogênese, as diferenças entre bebidas energéticas e estimulantes e a alimentação e metabolismo de uma forma geral, além de trabalharem a interpretação dos gráficos dos testes glicêmicos (característica esta presente nas competências e habilidades dos PCN's).

A escolha do tema, que normalmente é trabalhado na segunda série do ensino médio, vai ao encontro da LEI No 13.666 (2018), recém aprovada, que altera a Lei no 9.394, de 20 de dezembro de 1996 (Lei de Diretrizes e Bases da Educação Nacional - LDB), para incluir o tema transversal da educação alimentar e nutricional no currículo escolar. Além disso ela mostra certa relevância já que trata de conceitos relacionados à saúde e ao funcionamento do corpo e, de uma forma geral, o aluno poderá construir a noção de saúde levando em conta fatores como o estilo de vida e o estado nutricional, a partir das pistas que o jogo apresenta. Além disso, o jogo permite uma discussão sobre bebidas energéticas e estimulantes. A escolha pela utilização da atividade lúdica teve como objetivo levar o conhecimento científico da temática de maneira mais dinâmica e divertida.

Dessa forma, ao escrevermos esse artigo tivemos como objetivo mostrar que o jogo consegue ampliar a visão dos discentes em relação às moléculas energéticas; e permitir que os alunos tenham um olhar diferenciado sobre os rótulos, principalmente sobre a tabela nutricional encontrada nas embalagens dos alimentos. 
DOI: https://doi.org/10.46667/renbio.v13i1.284

O jogo, na sua versão 1.0, foi aplicado em duas turmas do terceiro ano do Colégio de Aplicação do município de Macaé, no ano de 2018, logo após a aprovação do Comitê de Ética em Pesquisa do Hospital Universitário Clementino Fraga Filho e da Faculdade de Medicina da Universidade Federal do Rio de Janeiro (CEP/HUCFF/FM/UFRJ), sob parecer consubstanciado $\mathrm{n}^{\circ}$ 2.917.579 / CAAE: 93012318.5.0000.5257.

\section{0 jogo didático}

A produção desse material didático foi baseada em jogos de tabuleiros como War, Detetive e o Jogo "Célula a Dentro" (SPIEGEL et al., 2008), mas o fato de adaptá-lo à temática o fez único e bastante diferente dos citados.

O jogo apresenta um enredo, um tabuleiro, caderno de questões propostas, avatares e as cartas com dicas e pistas. O enredo e algumas cartas foram de criação própria do professorpesquisador, enquanto para os textos das outras cartas, foram utilizadas diversas fontes. As cartas foram elaboradas a partir de conceitos que envolvem o raciocínio lógico, a interpretação de gráficos, cálculos matemáticos simples, esquemas, tabelas, e a diferença energética entre lipídeos, proteínas e carboidratos. Todas essas cartas foram inseridas dentro de envelopes numerados de acordo com o tabuleiro (foto 1). Aspectos teóricos que constituem a atividade educativa foram introduzidos com o objetivo de destacar pontos de ligação entre o conteúdo que está sendo ensinado e o dia a dia dos alunos, como a diferença entre bebidas energéticas e estimulantes.

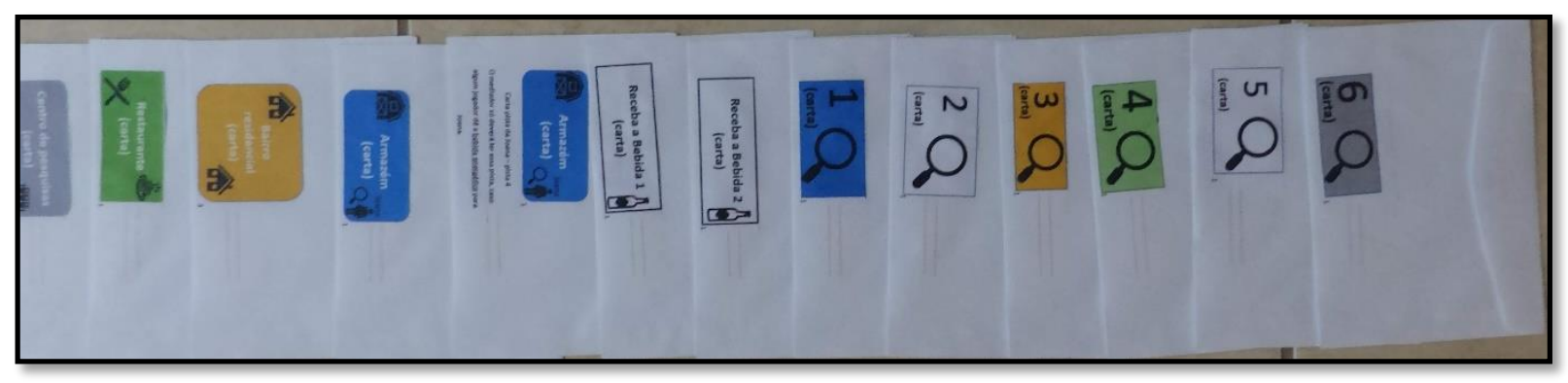

Foto 1: Arquivo pessoal (2018) - Envelopes com as cartas dicas e pistas

Com o intuito de contextualizar o conteúdo, foram elaboradas tabelas nutricionais a partir de alimentos comercializados (figura 1), embora a quantidade de cada nutriente das embalagens tenha sido extraída e/ou adaptada para porções de $10 \mathrm{~g}$ ou múltiplos de 10 para moléculas que fornecem energia. 
DOI: https://doi.org/10.46667/renbio.v13i1.284

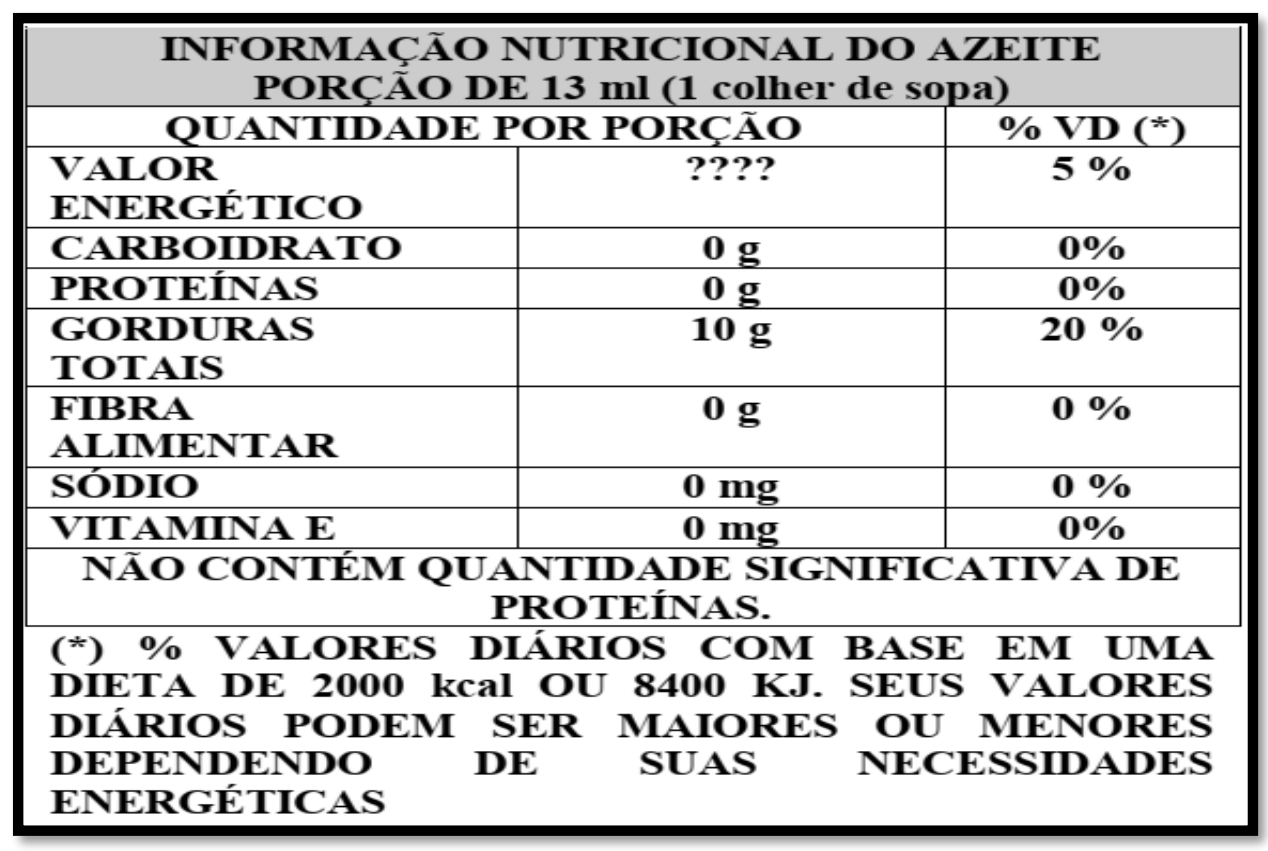

Figura 1: Informação nutricional do azeite adaptada.

O caderno de questões propostas foi elaborado a partir das pistas e tinha como intuito a leitura destas pistas para que fossem respondidas. A parte gráfica do jogo foi modelada a partir do programa Powerpoint 2016 da Microsoft $\AA$.

O jogo foi elaborado para atender tanto à demanda cooperativa, quanto à competitiva, embora achemos que a estratégia cooperativa seja mais viável pelo fator tempo. Para dar mais emoção à atividade, foram confeccionados avatares dos personagens acusados (foto 2) a partir do site Avatar Maker (https://avatarmaker.com/). 


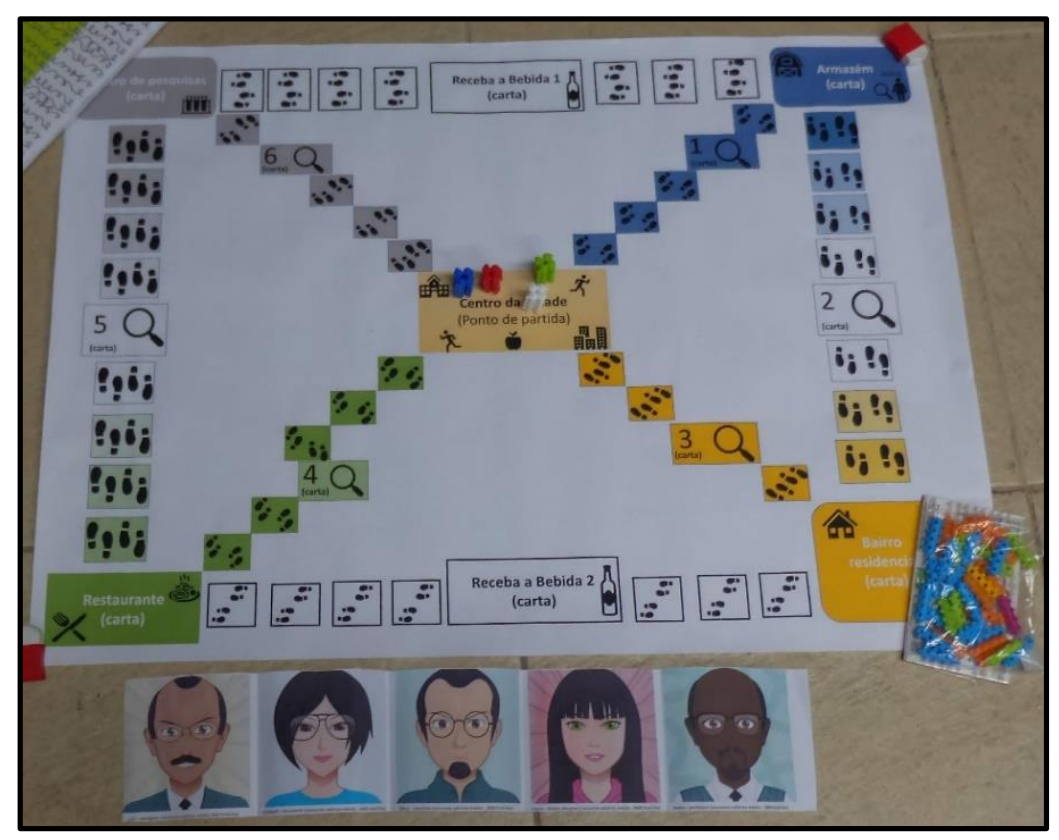

Foto 2: Arquivo pessoal (2018) - Tabuleiro impresso em papel A1, pinos ao centro e os avatares abaixo do tabuleiro.

\section{Como Jogar}

O jogo se baseia na solução de um caso: o desaparecimento de alimento do armazém de uma cidadezinha que se encontra isolada por causa de uma erupção vulcânica. A partir das pistas, os moradores (detetives) em cooperação deverão descobrir o autor pelo sumiço do alimento e resolver o caderno de questões propostas.

\subsection{Organização das Equipes e Início do Jogo}

1- Em cada tabuleiro deverá ficar uma equipe, que será composta por, no mínimo 4, e, no máximo 12 jogadores, mais um mediador.

2- O mediador tem a função de: ler as orientações (regras) antes do início do jogo; ler a cartaproblema; mostrar os avatares dos personagens acusados para os jogadores; entregar os envelopes que contêm as cartas dicas e/ou pistas, quando o jogador parar no local; distribuir e recolher os "papeizinhos de energia"; distribuir os gráficos de cada personagem (gráfico 1), a serem preenchidos com as pistas para cada equipe.

3- Cada grupo (composto por 1 a 3 jogadores) deverá escolher o peão de sua preferência (num total de 4 peões) e posicioná-lo no ponto de partida.

4- Após o recebimento do caderno de questões propostas (quadro 1), cada equipe deverá lançar o dado para saber a ordem dos grupos. O número mais alto será o primeiro e se houver empate, deverá haver um desempate através de um novo lançamento entre os grupos que empataram. 


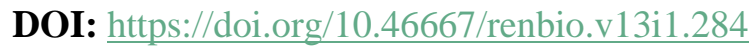

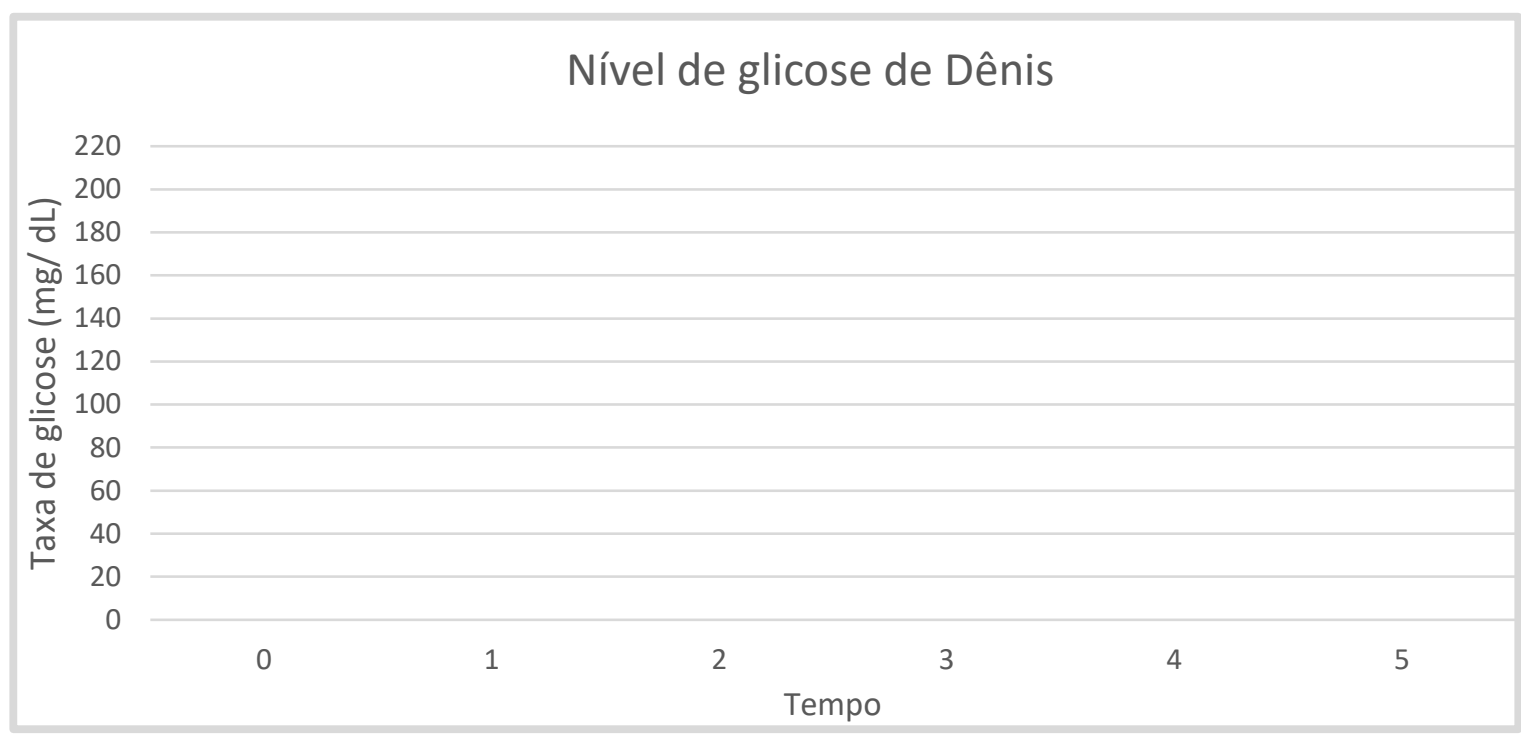

Gráfico 1 - Gráfico a ser preenchido com os dados de Dênis de acordo com os envelopes que contém as pistas.

QUADRO 1 - Caderno de questões propostas

1- Qual a quantidade de energia, em kcal, fornecida por um grama de gordura? (usar rótulo para eles fazerem os cálculos)

2- O que é metabolismo e qual a sua relação com a manutenção do corpo?

3- Qual é o "papel” da insulina em nosso corpo?

4- Para que servem os nutrientes que compõem os nossos alimentos?

5- Como as células do corpo que dependem de glicose conseguem energia durante a privação (falta) de carboidratos?

6- Qual a quantidade de energia, em kcal, fornecida por um grama de carboidrato?

7- Todos os nutrientes (lipídios, carboidratos e proteínas) fornecem a mesma quantidade de energia? Explique.

8- Diferencie bebidas energéticas das estimulantes. 
DOI: https://doi.org/10.46667/renbio.v13i1.284

\subsection{Movimentação Durante o Jogo}

Para se movimentarem no tabuleiro, os jogadores precisarão de energia. Essa energia será distribuída em pedacinhos de papel (figura 2). Cada pedacinho corresponde a $10 \mathrm{kcal} \mathrm{e}$ todos receberão 7 papeizinhos (fichinhas) para iniciarem as suas investigações, ou seja, receberão o correspondente a $70 \mathrm{kcal}$ (uma maçã). Com essa energia, eles deverão investigar as pistas e procurar mais papeizinhos de energia que se encontram espalhados no tabuleiro. Os jogadores têm cinco rodadas para descobrirem quem foi o autor do crime.

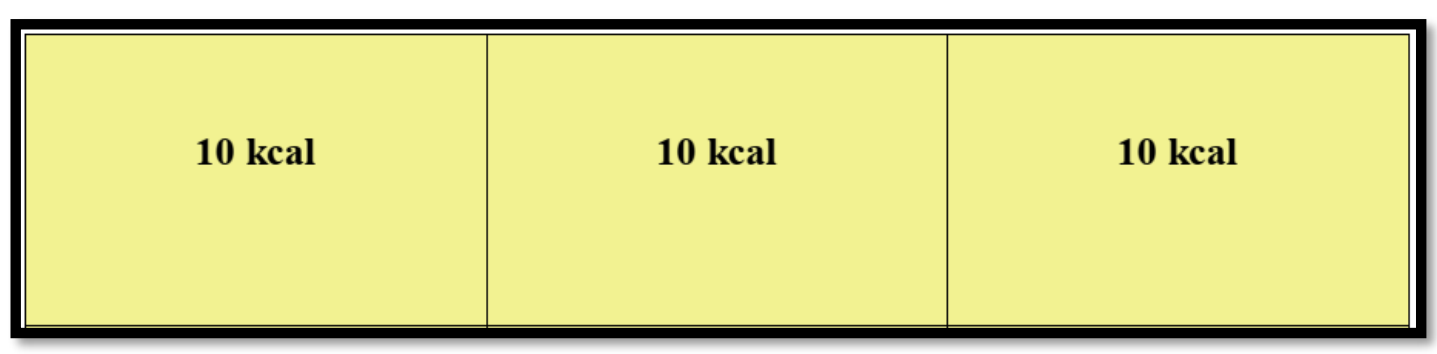

Figura 2: Papeizinhos de energia

\subsection{Movimento no Tabuleiro}

Os jogadores deverão movimentar seus peões ao longo do tabuleiro para obterem as pistas. Cada grupo joga o dado na sua vez e move seu pino por tantas casas quanto forem os pontos sorteados e a energia que tiver disponível. Caso o detetive não tenha energia o suficiente para se locomover pelo tabuleiro, ele poderá pegar emprestado de outro detetive. Se o número tirado no lançamento do dado ultrapassar o necessário para entrar nas casas contendo as pistas, o grupo terá a opção de dispensar os números restantes e consultar o seu envelope.

Para se locomover pelo tabuleiro, a fim de coletar dicas e pistas, o jogador deverá lançar o dado para passar por cada quadradinho, onde cada avanço consome cerca de $10 \mathrm{kcal}$ do jogador. Por exemplo: caso o jogador tire o número 4 no dado e escolha o caminho azul, ele cairá na casa da dica 1 e gastará $40 \mathrm{kcal}$, que são equivalentes aos quatro quadradinhos. Para ter acesso à dica 1, o jogador deverá entregar para o mediador os papeizinhos que correspondem ao gasto calórico para se locomover (figura 3). 
DOI: https://doi.org/10.46667/renbio.v13i1.284

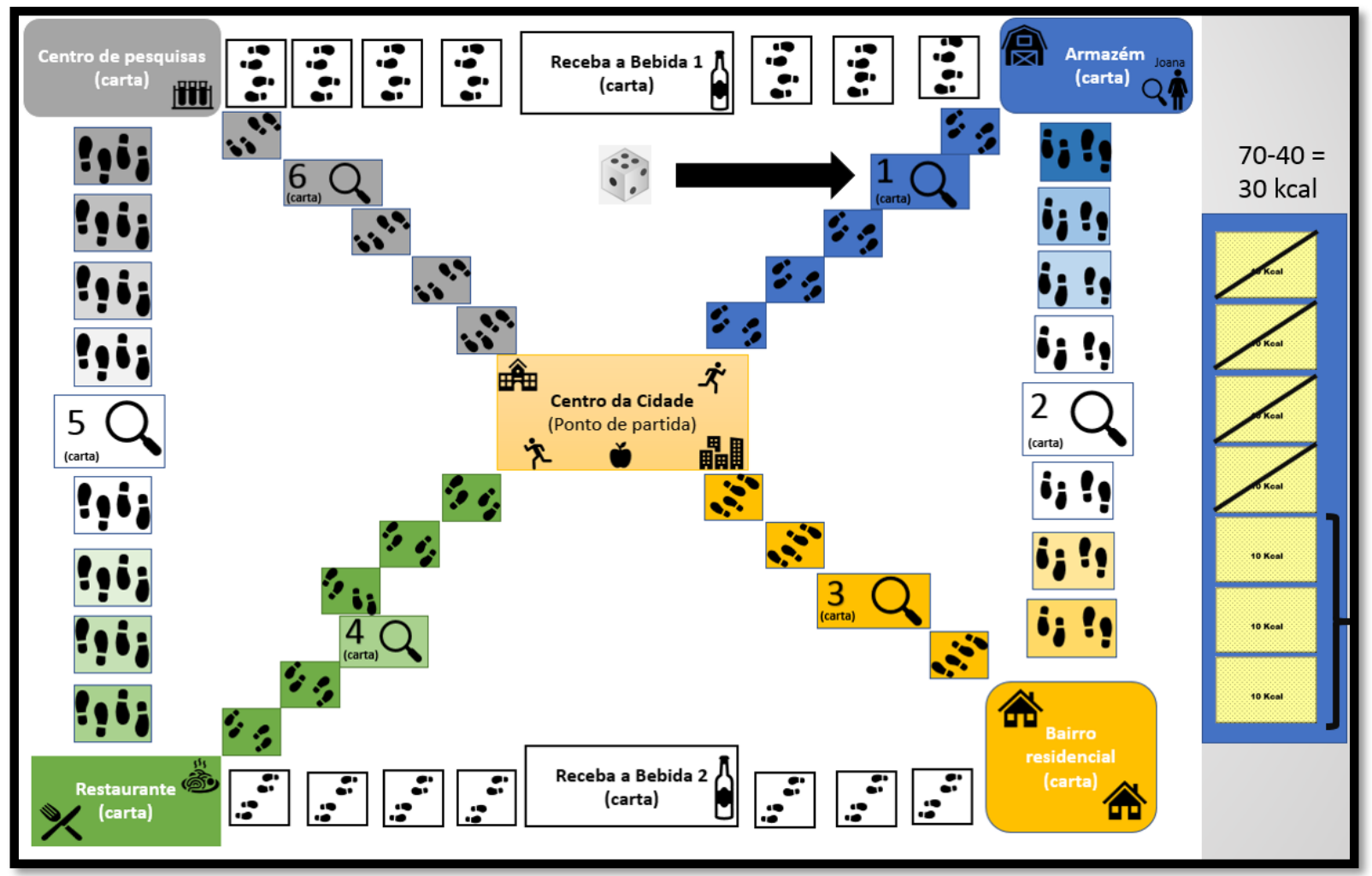

Figura 3: Movimento do peão do jogador que tirou o número 4 no dado e os gastos calóricos desse movimento.

\subsection{Cartas}

Cada carta contém informações diferentes, que deverão ser lidas e discutidas em voz alta. As conclusões da discussão deverão ser registradas no Caderno de questões propostas. Uma vez lida, a Pista tem de ser devolvida ao Mediador. Não é permitido aos jogadores consultarem mais de uma Pista ao mesmo tempo. Uma mesma Pista poderá ser consultada por todos da equipe.

\subsection{Propondo a Solução}

Terminado o tempo de 5 rodadas, o mediador recolhe e guarda todas as cartas com as pistas. As equipes de um mesmo tabuleiro deverão se juntar formando um único grupo. Cada equipe apresentará às demais as informações das pistas que foram capazes de coletar durante a partida (nesse momento, a consulta ao Caderno de Anotações é livre). O grupo formado por todas as equipes tem de 10 a 20 minutos para discutir e propor uma solução única para o caso. 
DOI: https://doi.org/10.46667/renbio.v13i1.284

3.6 Final do Jogo

A solução encontrada após o fim das cinco rodadas deve ser lida em voz alta, junto com as respostas dadas no caderno de questões propostas. Se a resposta do grupo estiver correta, parabéns! Todos ganharam! Note que nesse modo de jogar não há um jogador ou grupo vencedor. Todos deverão jogar contra o tempo e por isso, este deverá ser rigorosamente controlado.

\section{Metodologia}

A presente proposta pedagógica foi planejada para ser aplicada num único dia e com duração de 3 horas. Os sujeitos da pesquisa foram estudantes da $3^{\text {a }}$ série do Colégio de Aplicação da prefeitura de Macaé que participavam da disciplina eletiva PAE (programa de aprofundamento de estudos), no ano de 2018, na área de Ciências da Natureza. Para participarem dessas eletivas, os alunos devem fazer a inscrição no início do ano letivo. Todos os alunos que participaram da pesquisa estavam inscritos e frequentavam a disciplina. Essa eletiva tem por objetivo aprofundar os estudos em Física, Química e Biologia.

$\mathrm{Na}$ primeira turma, os discentes foram divididos em dois grupos de 6 pessoas, totalizando 12 alunos e na segunda turma dois grupos de 5 pessoas, totalizando 10 alunos e posteriormente 9 , já que uma aluna teve que se ausentar por motivos médicos. Cada integrante do grupo recebeu o caderno de questões propostas (quadro 1), uma peça (peão) e os gráficos dos personagens a serem preenchidos com as pistas; o mediador recebeu a regra, o avatar dos personagens acusados e os envelopes que continham as cartas com as dicas ou pistas. Foram feitos registros no diário de campo do pesquisador e um áudio foi gravado da discussão sobre os acusados, ou seja, como eles chegaram à conclusão. Ao terminarem o jogo, os grupos foram motivados a lerem as suas respostas de forma sequenciada. Por exemplo, o grupo 1 leu a resolução número 1 e o grupo 2 leu a resolução número 2 e assim por diante. Quando o grupo ouvinte discordava de uma resposta era permitido que esse grupo lesse a sua resposta e de forma cooperativa se chegava a um consenso da melhor resolução para a pergunta.

Para investigar a influência do jogo sobre a percepção dos alunos, foram utilizados dois instrumentos de avaliação (questionários) que foram aplicados aos discentes em dois momentos diferentes: um questionário antes da aplicação do jogo, chamado de pré-teste e um questionário após a aplicação, denominado de pós-teste. Tais atividades compartilhavam 8 questões em comum.

No pré-teste, além das mesmas questões do pós-teste, havia também perguntas com o objetivo de averiguar se os discentes tinham costume de ler as informações nutricionais das embalagens e caso tivessem, se isso estaria relacionado a algum tipo de necessidade fisiológica, como alergias ou intolerância e o que eles procuravam quando liam tais informações. 
DOI: https://doi.org/10.46667/renbio.v13i1.284

O pré-teste foi composto também por questões diagnósticas, tais como: se os participantes haviam tido esse contato com os conteúdos relativos ao metabolismo celular e quanto tempo fazia que haviam visto esse tema pela última vez.

O conjunto de perguntas dos questionários permite investigar e avaliar a percepção dos alunos sobre a temática, embora não seja minucioso em relação ao conceito que o aluno dispõe sobre determinado tema. No pós-teste, além das mesmas questões do pré-teste, havia também uma questão que os indagava se o jogo de alguma forma os tinha ajudado a ter um olhar diferenciado sobre a tabela nutricional dos alimentos. As respostas foram preparadas utilizando-se a escala de LIKERT, com emoticons (figura 4).

O jogo te ajudou de alguma maneira a ter um olhar diferenciado sobre a tabela nutricional dos alimentos? Para responder à pergunta, marque um emoticon abaixo, onde o número 5 representa que ajudou bastante e o número 1 representa não ajudou.
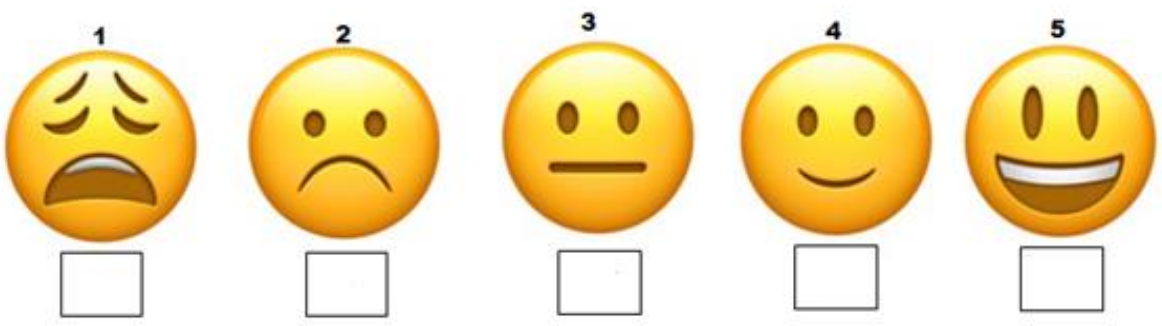

Figura 4: Pergunta para averiguar se o jogo os ajudou a mudar o olhar sobre as informações nutricionais (Escala LIKERT).

A utilização do segundo questionário (pós-teste) foi fundamental para identificar se houve a integração do novo conhecimento à estrutura intelectual do discente por meio da interação entre a nova informação e os conhecimentos prévios.

Por questões de praticidade e logística, resolvemos analisar algumas questões dos pré e pós-testes que estivessem relacionadas aos objetivos deste artigo. 
DOI: https://doi.org/10.46667/renbio.v13i1.284

\section{Resultados e Discussão}

Através da análise das questões A, B e C do pré-teste (figura 5), conseguimos demonstrar a visão dos discentes pesquisados sobre a tabela nutricional dos alimentos. A partir dessa análise foi gerado o gráfico 2 que nos permitiu concluir que uma boa parte dos alunos não tem o costume de ler as informações nutricionais (10 alunos), mas quando leem, representado por 15 alunos, afirmam que costumam ler a quantidade de calorias fornecidas pelos alimentos. Entretanto, 13 alunos declararam não ser essa informação um empecilho para o consumo desse tipo de alimento.

A- Você costuma ler as informações nutricionais dos alimentos, assim como o personagem abaixo?

( ) $\operatorname{sim} \quad($ ) de vez em quando ( ) nunca

Você, consumidor, está lendo o rótulo do pão de forma e se depara com a informação abaixo.

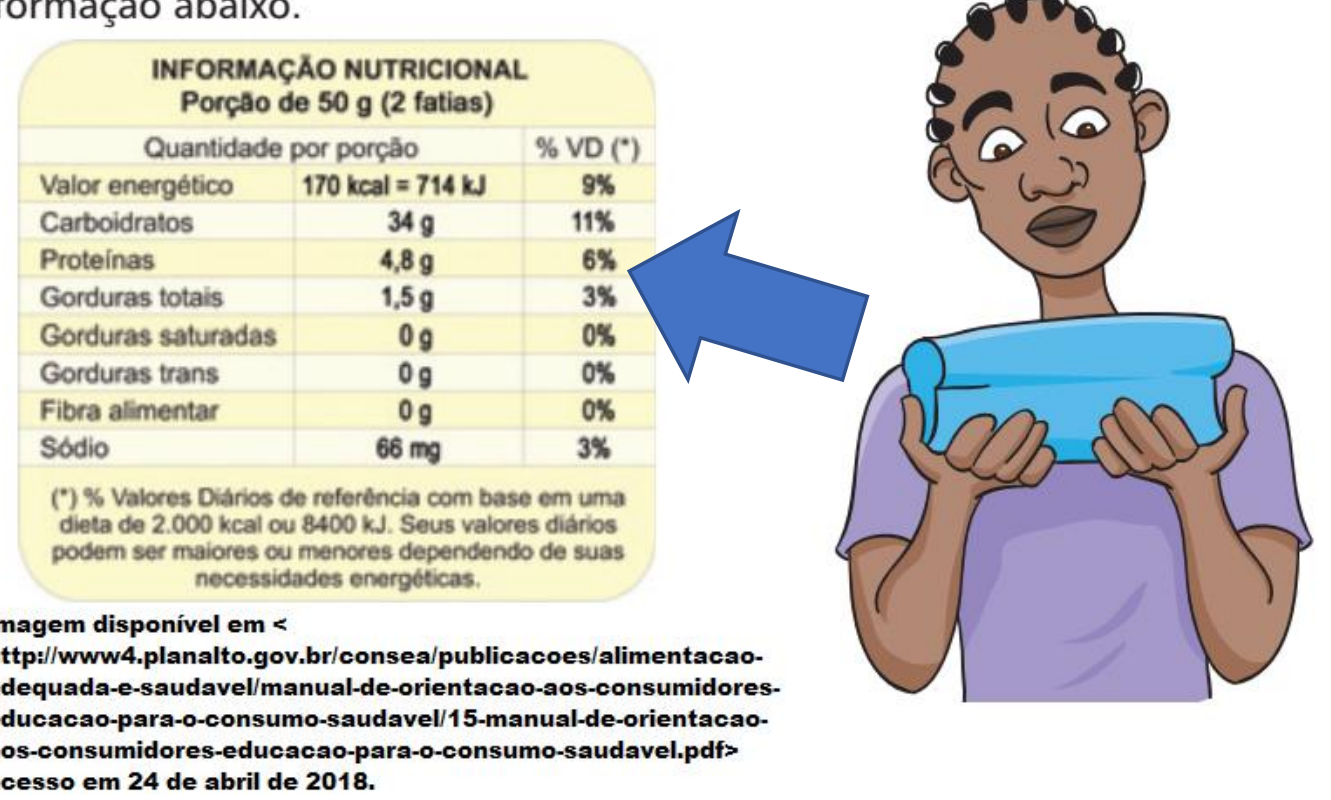

B- Se costuma, você observa a quantidade de energia em kcal disponível?

C- Você se preocupa em relação à quantidade de energia fornecida por cada alimento?

Figura 5: Questões A, B e C do pré-teste. 


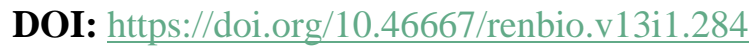

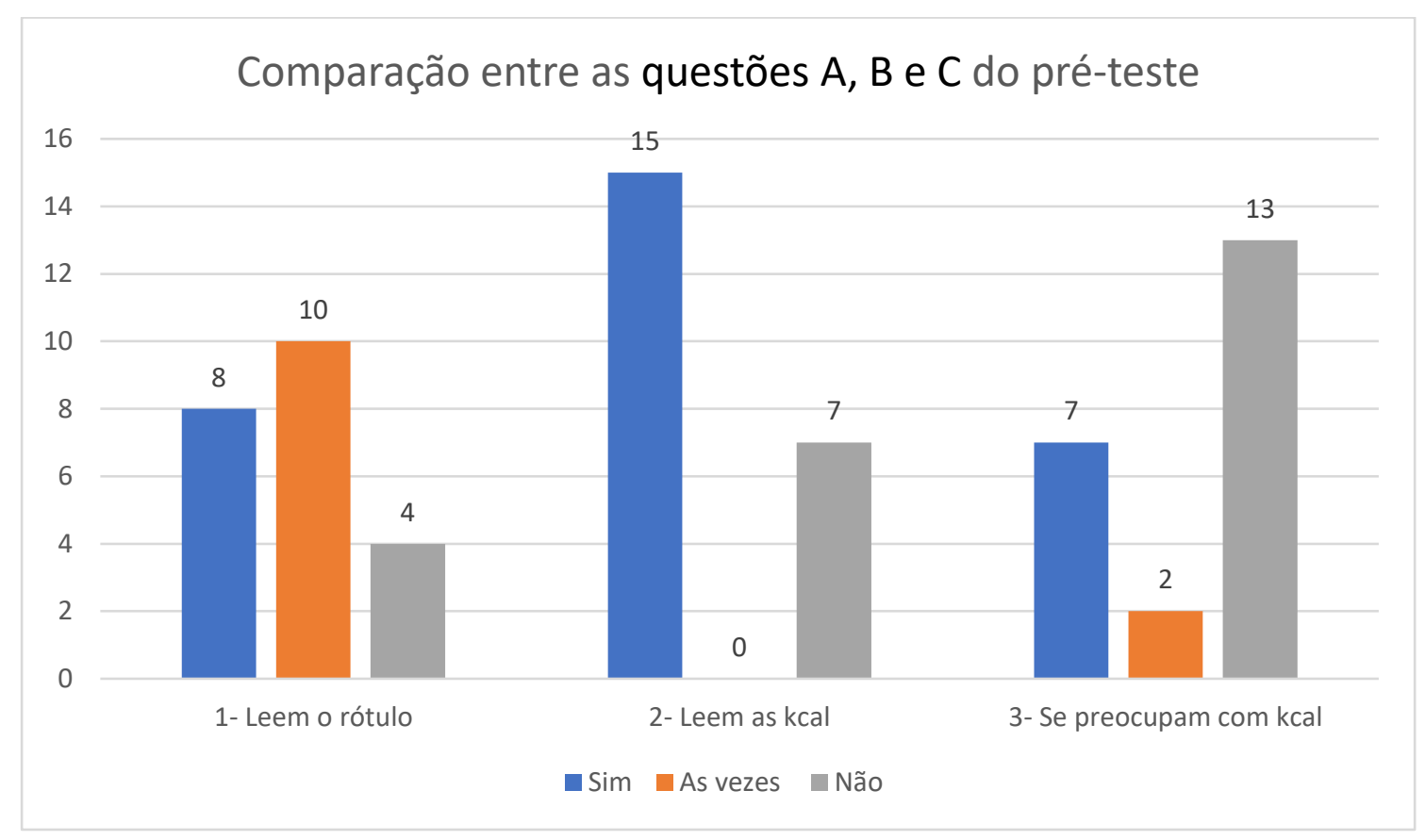

Gráfico 2: Comparação dos dados do pré-teste.

Ao analisarmos a percepção dos alunos em relação às moléculas energéticas, questão 2 (figura 2), podemos notar uma evolução em relação ao questionário anterior, quando comparamos somente as proteínas e os lipídios (gráfico 3).

2- Qual(is) molécula(s) é/são usada(s) nas células para a produção de ATP?

( ) Proteínas ( ) sais minerais ( ) Gordura ( ) vitaminas （ ) carboidratos

Figura 2: Questão 2 dos pré e pós-testes 
DOI: https://doi.org/10.46667/renbio.v13i1.284

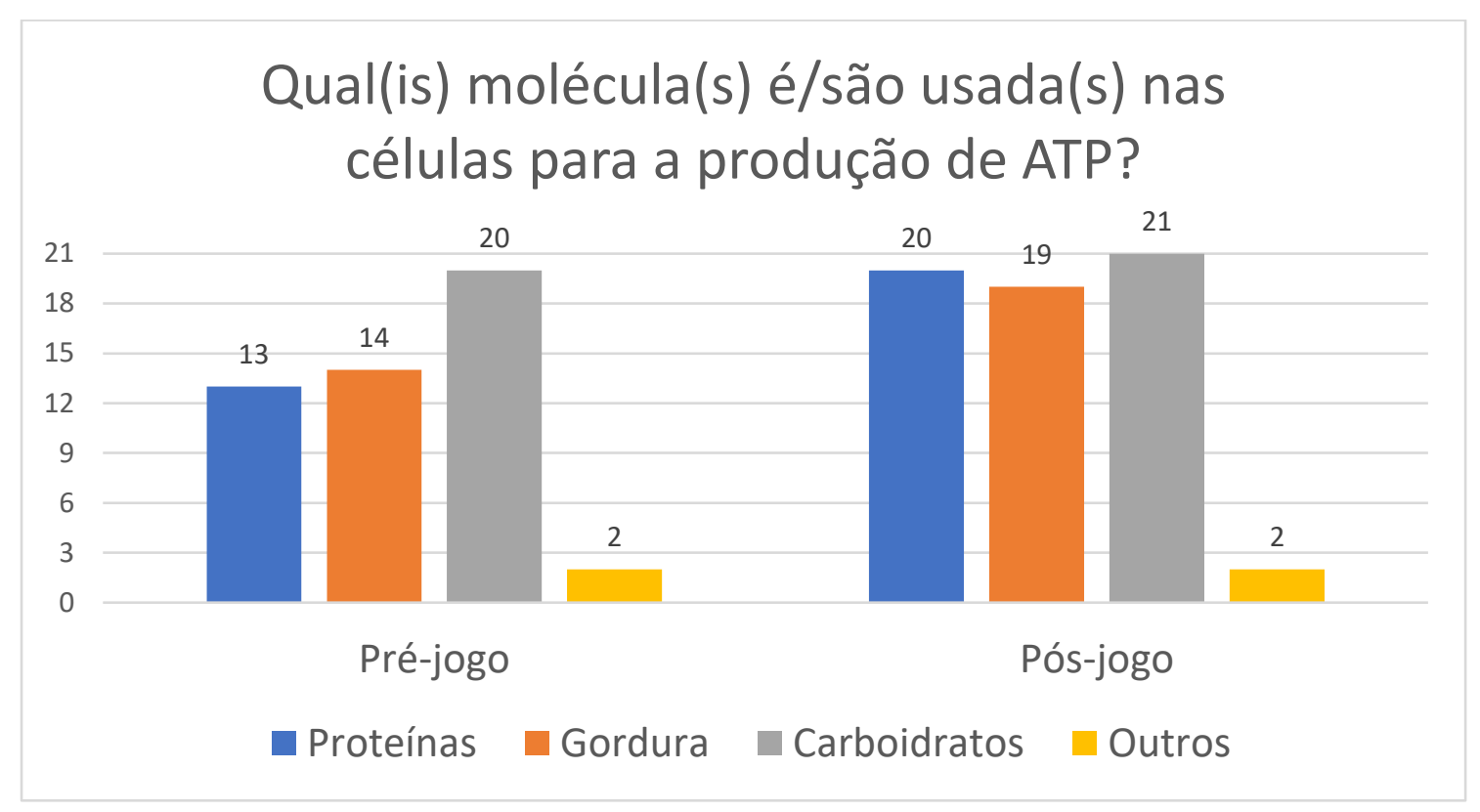

Gráfico 3 - Padrão de respostas dos alunos à questão número 2 do pré e do pós-teste.

Conforme podemos notar no gráfico 3, o perfil de respostas dos alunos após o jogo mudou quando comparado ao de sondagem. No pré-teste podemos observar que a maioria reconhece os carboidratos como capazes de fornecer ATP e um menor número de alunos reconhece as proteínas e lipídios também como fontes de energia. Tal fato está relacionado às aulas dadas sobre bioenergética no início do ano letivo. Após a aplicação do jogo, observamos que uma proporção significativa dos alunos passou a reconhecer tanto as proteínas, quanto a gordura como moléculas utilizadas na produção de ATP. Este resultado mostra que o jogo serviu como revisão ou os ajudou a mudar as suas percepções em relação a essas duas outras moléculas. Tal fato, provavelmente, está relacionado à contextualização do conteúdo a partir da análise dos rótulos de alimentos que continham isoladamente proteínas, carboidratos e lipídios.

Ao indagarmos, no pós-teste, se o jogo de alguma maneira havia colaborado para eles terem um olhar diferenciado sobre a tabela nutricional (figura 4), percebemos, de uma forma geral, que os alunos, em sua maioria (90\%), marcaram as opções que mostravam que o jogo de alguma forma poderia influenciar na leitura da tabela nutricional (gráfico 4). 
DOI: https://doi.org/10.46667/renbio.v13i1.284

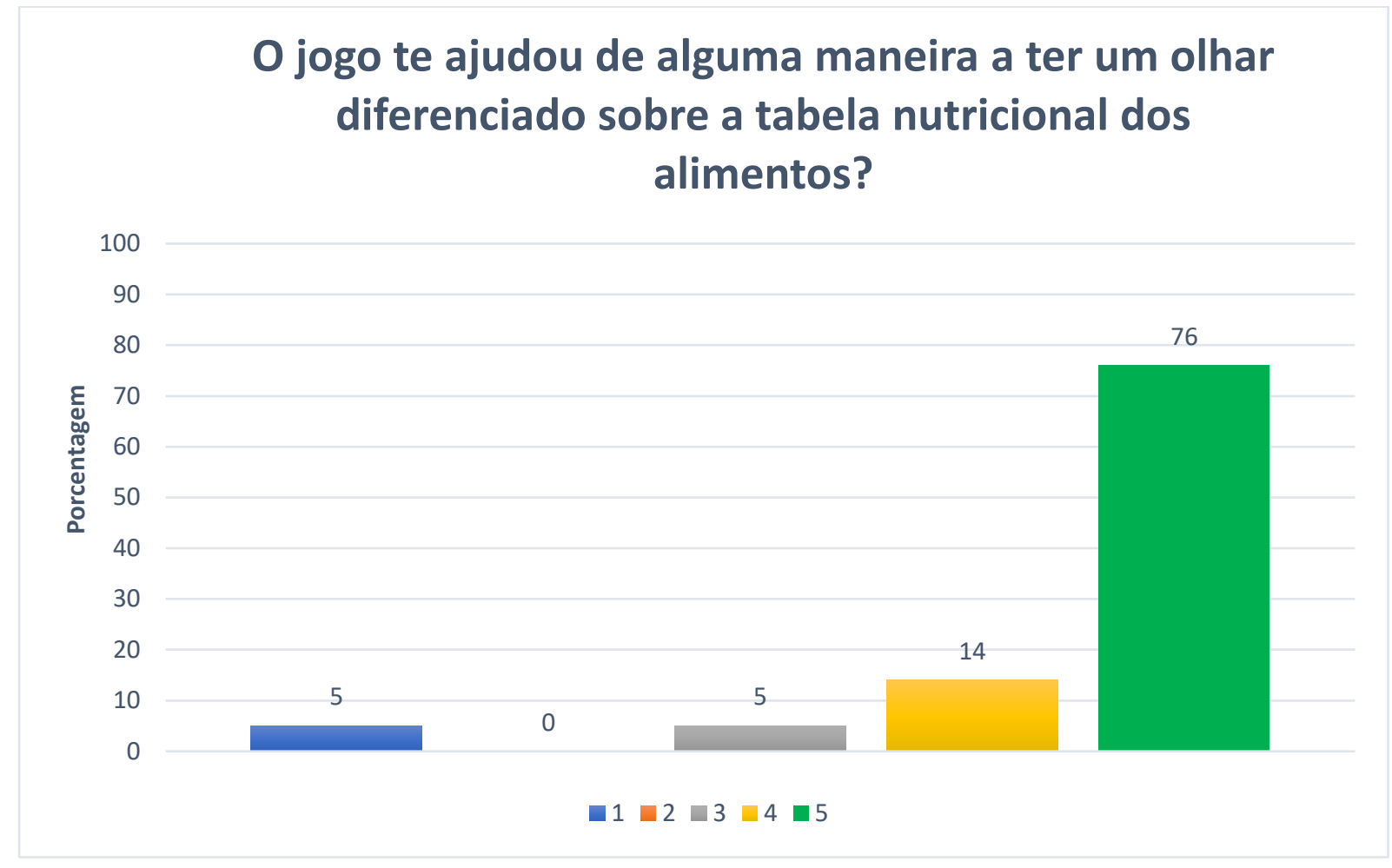

Gráfico 4-Percepção dos estudantes sobre a influência do jogo na análise da tabela nutricional

Sendo assim, a partir dos resultados obtidos, podemos afirmar que o jogo "Sobrevivência" colaborou no aprendizado do conteúdo sobre as moléculas energéticas e na leitura da informação nutricional dos alimentos.

\section{Considerações Finais}

O presente trabalho, portanto, permitiu a participação dos alunos em discussões sobre a temática estudada e a reunião em grupos buscou promover o respeito às diferentes formas de pensar, a convivência e a cooperação entre os integrantes.

Acreditamos que a promoção da cooperação é de extrema importância, já que em nossa prática diária presenciamos constantemente em sala de aula a formação de grupos que competem uns com os outros. Esta relação, geralmente, não é benéfica para todos. Portanto, consideramos que ao incentivarmos os trabalhos cooperativos, promoveremos a melhora na qualidade das relações sociais na escola, onde o jogo "Sobrevivência" mostrou-se uma boa estratégia para desenvolver essa proposta.

Outro fator que pode ter contribuído para o sucesso da estratégia foi o fato de que, no momento da discussão, diferentes alunos terem participado e contribuído no aprendizado dos outros, já que na discussão, os diferentes grupos poderiam dar suas contribuições. Sendo assim, os alunos tiveram a oportunidade de ensinar e aprender uns com os outros, discutir, compartilhar seus resultados e chegar a um consenso. 
DOI: https://doi.org/10.46667/renbio.v13i1.284

Entende-se que, a partir dos dados analisados, a escolha deste método de ensino, que partiu do cotidiano do discente, promoveu a participação de todos, além de ter permitido maior interesse e motivação por parte deles. As resoluções das questões por intermédio das pistas e a discussão sobre quem era o responsável pelo sumiço da comida permiti-nos afirmar que os grupos conseguiram chegar a uma conclusão sobre o "caso" do jogo.

O jogo, ao simplificar alguns dados da tabela e trabalhar determinados conceitos, além de ter uma característica lúdica, permitiu que os alunos tivessem um olhar diferenciado sobre os rótulos. Acredita-se que o jogo possa ser, de uma forma geral, um ponto de partida para que os alunos tenham um outro olhar sobre as informações nutricionais e possam ver essa parte da embalagem como um importante instrumento para reduzir os excessos e os danos à saúde a partir de suas escolhas alimentares, criando deste modo uma dieta habitual mais saudável.

A aplicação do jogo possibilitou também maior interesse dos discentes em relação ao conteúdo sobre nutrição e metabolismo energético, mostrando a importância de jogos didáticos como um recurso eficaz no processo de ensino-aprendizagem de uma forma lúdica e motivadora, promovendo, assim, a alfabetização científica.

Algumas dificuldades foram observadas e sugestões foram realizadas para que o jogo se tornasse mais dinâmico e que as pistas pudessem direcionar os alunos aos fatos e não os confundissem. A partir da análise dos resultados, o jogo de tabuleiro "Sobrevivência" cumpriu com o seu objetivo pedagógico e mostrou-se uma ótima alternativa para a introdução/revisão de conceitos relacionados à temática.

O jogo compõe-se de material acessível aos professores por causa do seu baixo custo, apresentou boa aceitação por parte dos alunos e flexibilidade, por poder ser adaptado - com a substituição de pistas - à realidade de cada escola.

\section{Referências Bibliográficas}

BORDENAVE, J. D; PEREIRA, A. M. Estratégias de ensino-aprendizagem. 30.ed. Petrópolis, RJ: Vozes, 2010.

CAMPOS, L. M. L.; BORTOLOTO, T. M.; FELICIO, A. K. C. A produção de jogos didáticos para o ensino de ciências e biologia: uma proposta para favorecer a aprendizagem. Cadernos dos Núcleos de Ensino, São Paulo, p. 35-48, 2003. Disponível em: http://www.unesp.br/prograd/PDFNE2002/aproducaodejogos.pdf. Acesso em: Dezembro 2019.

KRASILCHIK, M. Prática de ensino de biologia. 4. ed. São Paulo: Universidade de São Paulo, 2016. 
LUZ, M. R. M. P., OLIVEIRA, G. A.; SOUSA, C. R.; DA POIAN, A. T. Glucose as the sole metabolic fuel: the possible influence of formal teaching on the establishment of a misconception about energy-yielding metabolism among students from Rio de Janeiro, Brazil. Biochem. Mol. Biol. Educ., v.36, p.407-416, 2008.

OLIVEIRA, G. A. O metabolismo energético no ensino médio: diagnóstico e proposta de ensino. Dissertação de mestrado. Departamento de Bioquímica Médica (ICB/UFRJ). 2003

SPIEGEL, C. N; ALVES, G. G; CARDONA, T.S; MELIM; L.M.C.; LUZ, M.R.M.P., ARAÚJO-JORGE, T.C.; PONS, H. A. Célula Adentro (discovering the cell) an educational game in cell and molecular biology for secondary-level students. Journal of Biology

Education, v. 43, n.1, p.27-35, 2008. 